\title{
INBREEDING COEFFICIENT IN SIMULATED OPEN NUCLEUS BREEDING SCHEME IN EGYPTIAN BUFFALO
}

\author{
A.I. Sayed ${ }^{1}$, S.A. Abdel-Salam ${ }^{1}$, Manal Elsayed ${ }^{2}$, S. Abou-Bakr ${ }^{1}$ \\ 1- Department of Animal Production, Faculty of Agriculture, Cairo University, Gamaa Street, Giza, \\ Egypt, 2- Department of Animal Production, Faculty of Agriculture, Ain Shams University, Shubra \\ El-Khema, Cairo, Egypt
}

\section{SUMMARY}

Simulated Populations with one record were generated with assumed mean (0) and variance (1) milking Buffalo populations. Four different population sizes (z): 10,000, 25,000, 50,000 and 100,000 animals were generated. Populations were composed by four generations obtained by selection of sires and dams from the previous generation. Mating ratio (male: females) was designed to differ from 1:25 to 1:100 and from 1:1000 to 1:5000. The objective of this study was to evaluate the changes in the inbreeding coefficient according to some alter factors (generation, mating ratios, population size, fraction of total population in nucleus, proportion of all males born used as sires, fraction of base sires born in nucleus, and fraction of base dams born in nucleus) in simulated open nucleus breeding schemes in Egyptian buffaloes. The Inbreeding coefficient increased significantly $(P<0.05)$ with the generation number. The inbreeding coefficient in the nucleus increased from 0.0012 in (G1) to 0.0057 in (G4) in the nucleus herd, and from 0.0008 in G1 to 0.0064 in G4 in the base herd. Moreover, the inbreeding coefficient increased by widening mating ratio in natural mating and artificial insemination. Significant differences $(P<0.05)$ in inbreeding coefficient were observed between different mating ratios $(M R)$. Inbreeding coefficient decreased significantly $(P<0.05)$ by increasing population size (z). Increasing z from 10000 to 25000 resulted in a decrease of $43 \%$ in inbreeding coefficient in both the nucleus and the base. Increasing (z) from 25000 to 50000 resulted in an increase of $30 \%$ in inbreeding coefficient in both the nucleus and the base. Finally, there were no significant differences in the inbreeding coefficient when the population size increased from 50000 to 100000.

\section{Keywords: Nucleus, inbreeding coefficient, population size, mating ratio}

\section{INTRODUCTION}

Inbreeding generated by the mating of relatives. Genetically, inbreeding increases homozygosity in the offspring. When the animals are artificially mated and there are a few numbers of elite sires in use, some degree of inbreeding cannot be avoided. Nevertheless, planning for mating program can minimize its level to minimize its effect on the economic traits (Khan, 2007).

Genetic improvement of livestock faces a lot of constrains to have the appropriate balance between high selection intensity of a small number of parents in the current generation and maintenance of enough quantitative genetic variation to allow a significant response in future generations. Recent advances in genetic selection programs tend to increase the annual response to selection, but rates of inbreeding have likewise increased significantly (Quinton et al., 1992). Several studies indicated the relevance of using open nucleus breeding scheme to reduce the rate of inbreeding (James, 1977, Bondoc and Smith, 1993, Dixit and Sadana, 1999, Phillips, 2001).
In the short term, increased genetic gain associated with increased inbreeding will, in the long term, lead to decrease genetic gain due to declines in fitness and genetic variance. Both genetic progress and inbreeding appear to be increasing at an increasing rate in today's commercial livestock populations (Quinton et al., 1992). Inbreeding can affect the genetic gain through decreased reproductive rate. The loss of response due to inbreeding effects on reproduction ranged from $25 \%$ in small herds to $8 \%$ in large herds (Meszaros et al., 1998).

This paper aims to calculate the inbreeding coefficient and investigate the factors affecting the rate of inbreeding in two-tier open nucleus breeding scheme.

\section{MATERIALS AND METHODS}

\section{Generation of the simulated populations of buffaloes:}

Simulation technique was used to generate population of buffaloes with one milk record for each buffalo. A total number of 3526 lactation records of 2179 buffaloes recorded by Cattle Information Systems/Egypt (CISE, 2007) of the Faculty of Agriculture, Cairo 
University during the period from 1990 to 2006 were used to estimate various parameters (Table 1) which were used to generate simulated populations.

Populations were generated using stochastic Monte Carlo simulation procedure of SAS (2004) with assumed mean (0) and variance (1). Simulation was replicated four times to generate four different sizes of populations: $10,000,25,000, \quad 50,000$ and 100,000 animals. Four generations were generated by selection of progenies with the highest breeding values for milk production to be sires and dams of the next generation. Selected bulls and heifers were mated at random.

The structure of the open nucleus breeding scheme and gene migration was explained by Abdel-Salam et al. (2010).

The genotypes of animals were simulated by the following formula (1) according to (Meuwissen, 1991):

$g_{i}=1 / 2 g_{s}+1 / 2 g_{d}+a_{i} \sqrt{0.5 h^{2} \sigma_{p}^{2}}$

Where $g_{i}, g_{s}$, and $g_{d}$ are the additive genetic values of individual $i$, its sire (s) and its dam (d), respectively, $\mathrm{h}^{2}$ is the estimate of heritability in population $\left(h^{2}=0.17\right), \sigma_{p}^{2}$ is the phenotypic variance, $a_{i}$ is the random number from the distribution $\mathrm{N}(0,1)$ and $\sqrt{0.5 h^{2} \sigma_{p}^{2}}$ is the Mendellian sampling term.

The record of buffalo $i$ was simulated by the following formula (2) according to (Meuwissen, 1991):

$$
\mathbf{Y}_{\mathbf{i}}=\boldsymbol{\mu}+\mathbf{g}_{\mathbf{i}}+\mathbf{e}_{\mathbf{i}}
$$

Where $Y_{i}$ is the lactation of the $i^{\text {th }}$ buffalo, $\mu$ is the average total milk yield, $\mathrm{g}_{\mathrm{i}}$ is the additive genetic value of individual $i, e_{i}$ is the environmental effect of the $i^{\text {th }}$ buffalo and assumed to equal $\boldsymbol{\sigma}_{\mathrm{e}} \mathbf{a}_{\mathbf{i}}, \sigma_{\mathrm{e}}$ is the square root of the error variance and $a_{i}$ is the random number from the distribution $\mathrm{N}(0,1)$.

\section{Generated generations:}

Simulation of next generations was generated by random mating of selected males and females of progenies for replacement from previous generation. The genotypes of animals were simulated by the above mentioned formula (1).

\section{Calculating the inbreeding coefficient:}

The rate of inbreeding in each generation for both nucleus and base was also determined using the methodology of James (1977).

Relationship coefficient that used to estimate the inbreeding coefficient is calculated using the Coancestry, Inbreeding (F), Contribution software presented by Sargolzaei et al., (2006).
Inbreeding coefficient for the nucleus and the base was analyzed according to the following statistical models:

$\mathbf{F}_{\mathrm{Nijklmn}}=\mu+G_{\mathrm{i}}+z_{\mathrm{j}}+p_{\mathrm{k}}+a_{\mathrm{l}}+M R_{\mathrm{m}}+\mathrm{e}_{\mathrm{ijklmn}} \quad$ (3)

$\mathbf{F}_{\text {Bijlmnop }}=\mu+G_{\mathrm{i}}+z_{\mathrm{j}}+a_{\mathrm{l}}+M R_{\mathrm{m}}+w_{\mathrm{n}}+y_{\mathrm{o}}+\mathrm{e}_{\mathrm{ijlmnop}}$ (4)

Where $\mathbf{F}_{\text {Nijklmn }}$ is the inbreeding coefficient in the nucleus;

$\mathbf{F}_{\text {Bijlmnop }}$ is the inbreeding coefficient in the base;

$\mu$ is the average inbreeding coefficient;

$G_{\mathrm{i}}$ is the effect of generation, $\mathrm{i}=(1,2 \ldots 4)$;

$z_{\mathrm{j}}$ is the effect of population size, $\mathrm{j}=(10000$, 25000, 50000, 100000);

$p_{\mathrm{k}}$ is the effect of fraction of total population in nucleus, $\mathrm{k}=(0.05,0.10)$;

$a_{1}$ is the effect of proportion of all males born used as sires, $\mathrm{l}=(0.05,0.10,0.20)$;

$M R_{\mathrm{m}}$ is the effect of mating ratio, $\mathrm{m}=(1: 25$, $1: 50,1: 100,1: 1000,1: 2500,1: 5000)$;

$w_{\mathrm{n}}$ is the effect of fraction of base sires born in nucleus, $\mathrm{n}=(0.10,0.20,0,30,0.60,1,00)$.

$y_{\mathrm{o}}$ is the effect of fraction of base dams born in nucleus, $\mathrm{o}=(0.08,0.14,0.17) ; \mathrm{e}_{\mathrm{ijklmn}}$ and $\mathrm{e}_{\mathrm{ijklmnop}}$ is the residual term.

Significance of differences among means of inbreeding coefficient resulting from applying different input variables was tested using Duncan test procedure (SAS, 2004).

\section{RESULTS AND DISCUSSION}

The inbreeding coefficient in the nucleus increased significantly $(\mathrm{P}<0.05)$ by increasing generation number as shown in figure (1). The inbreeding coefficient was 0.0012, 0.0018, 0.0032 and 0.0057 for G1, G2, G3 and G4, respectively. The same trend was observed in the base, being $0.0008,0.0017,0.0033$ and 0.0064 for G1, G2, G3 and G4, respectively. The reason for this increase in inbreeding coefficient by advancing generations was the number of related animals increased over generations. Meuwissen (1997) reported that in a simulated closed nucleus programs from generation one (the base generation) until generation number ten the inbreeding coefficient increased by increasing generations. He showed that the inbreeding coefficient was $0.029 \%$ in the third generation and increased to $0.202 \%$ in the tenth generation.

Inbreeding coefficient decreased significantly $(P<0.05)$ by increasing population size $(z)$ as shown in figure (2). The decrease of inbreeding coefficient by increasing population size was due to decreasing the probability of mating with a relative (Falconer, 1989). This result in agreement with the results reported by Maiwashe et al. (2006) that calculate the inbreeding coefficients for four different population sizes of South African Ayrshire, Guernsey, Holstein and Jersey, respectively, 
the authors found an increase of the inbreeding coefficient by decreasing population size. Increasing population size $(z)$ from 10000 to 25000 resulted in a decrease of $43 \%$ in inbreeding coefficient in both the nucleus and the base. Increasing population size $(z)$ from 25000 to 50000 resulted in a significant increase of $30 \%$ in inbreeding coefficient in both the nucleus and the base. This fact may happens because the selection and culling policy of animals in both the nucleus and the base population was founded on the estimated breeding value for these animals and that led to an increase of the related animals. Also, the results showed that there were no significant differences in the inbreeding coefficient when the population size increased from 50000 to 100000.

Figure (3) shows the change of inbreeding coefficient with different mating ratios. Significant differences $(\mathrm{P}<0.05)$ were observed between $M R$ in natural mating and artificial inseminations. No significant differences $(\mathrm{P}>0.05)$ were shown within mating ratios in $\mathrm{NM}$ in both the nucleus and the base. The inbreeding coefficient of the nucleus was $0.0008,0.0009$, and 0.001 for the mating ratios (1: 25), (1: 50) and (1: 100), respectively. Increasing $M R$ from $1: 100$ to $1: 1000$ was accompanied by an increase in inbreeding coefficient from 0.001 to 0.004 . The inbreeding coefficient was 0.005 and 0.006 when using 1: 2500 and 1: 5000 in the nucleus, respectively. The result takes the same trend in the base. The inbreeding coefficients was $0.0005,0.0007$ and 0.001 mating ratios with no significant differences Increasing $M R$ from 1:100 to $1: 1000$ was accompanying an increase in inbreeding coefficient from 0.001 to 0.004 . The inbreeding coefficient was 0.0055 and 0.007 when using 1: 2500 and 1: 5000 in the base.

The increase of inbreeding coefficient with widening mating ratios was mainly due to the increase of selection intensity in males used as sires. These results agree with those of Gibson and Jeyaruban (1993) which reported that widening the mating ratio at a given female population size increases the selection intensity on the male side but also increases inbreeding rates due to smaller effective population size. Also, these results agree with those of Bosso (2006) who calculated the inbreeding coefficient in an open nucleus breeding scheme (5 sires and 200 females) of N'Dama cattle breed in West Africa, where the annual rate of inbreeding was estimated at $4.5 \%$ per generation. An intensive selection of sires increased the annual rate of inbreeding. Decreasing the selection intensity of sires resulted in a reduced rate of inbreeding; for example the rate was $2.3 \%$ when 10 sires were selected to service a population of 200 females. That shows clearly the effect of varying the number of sires and the size of the nucleus on the annual rate of inbreeding.

The proportion of males born used as sires had non-significant effect on the inbreeding coefficient in the nucleus and the base as shown in figure (4). The inbreeding coefficient in the base was higher than the inbreeding coefficient in the nucleus. This is mainly due to the high number of sires in the base and therefore decreasing the probability of mating with relatives. This result is different from the result found by Gibson and Jeyaruban (1993), who found that increasing the selection intensity of males led to an increase in inbreeding rates due to smaller effective population size.

Figure (5) shows change of inbreeding by changing fraction of base sires born in nucleus $(w)$. Inbreeding coefficient increased nonsignificantly $(\mathrm{P}>0.05)$ by increasing $(w)$ from 0.1 to $0.20,0.30$ or 0.60 . Differences between $w$ levels were significant $(\mathrm{P}<0.05)$ when all sires used in base $(w=1)$ came from the sires born in nucleus. The increase of the fraction of base sires born in nucleus ( $w$ ) was due to using small number of males that led to the decrease of the effective population size and increase of the inbreeding coefficient.

Inbreeding coefficient change by changing fraction of base dams born in nucleus $(y)$ is shown in figure (6). The inbreeding coefficient decreased with increasing $(y)$. Significant differences $(\mathrm{P}<0.05)$ are shown by increasing (y) from 0.08 to 0.14 . The inbreeding coefficient increased by increasing $(y)$ from 0.14 to 0.17 . The decrease of the migration rate of females born in nucleus $(y)$ to the base led to higher selection intensity of females selected in nucleus to transfer to the base.

The nucleus size had non-significant effect on the inbreeding coefficient in the nucleus. Increasing the nucleus size from 0.05 to 0.10 led to non-significant decrease of the inbreeding coefficient from 0.0032 to 0,0029 as shown in table (2).

\section{CONCLUSION}

The rate of increase of the inbreeding coefficient from applying the open nucleus breeding scheme for four generations was significant. It was concluded that increasing the inbreeding coefficient by changing $M R$ is mainly due to increasing the selection intensity in males used as sires. 


\section{REFERENCES}

Abdel-Salam, S.A., A.I. Sayed, Manal Elsayed and S. Abou-Bakr, 2010. Genetic gain in open nucleus breeding scheme to improve milk production in Egyptian Buffalo. Livest. Sci., 131:162.

Bondoc, O.L., and C. Smith, 1993. Deterministic genetic analysis of open nucleus breeding schemes for dairy cattle in developing countries. J. Anim. Breed .Genet., 110: 194.

Bosso, N.A., 2006. Genetic Improvement of Livestock in Tsetse Infested Areas in West Africa. Ph.D. Thesis, Wageningen University, Netherlands.

CISE, 2007. Buffalo herd book $1^{\text {st }}$ edition. Cattle Information Systems/Egypt, Faculty of Agriculture, Cairo University, Egypt.

Dixit, S.P., and D.K Sadana, 1999. Response of single trait selection in open nucleus schemes for buffalo breeding. Indian. J. Dairy. Sci., 52: 17.

Falconer, D.S., 1989. Introduction to Quantitative Genetics, $3^{\text {rd }}$ edition. Longman, New York,

Gibson, J.P., and J.G. Jeyaruban, 1993. The effects of Blup evaluations, population size and restrictions on selection of close relatives on response and inbreeding in egg-laying poultry. Centre for Genetic Improvement of Livestock Department of Animal and Poultry Science University of Guelph, Guelph, Ontario Canada.

James, J.W., 1977. Open nucleus breeding systems. Anim. Prod., 24: 287.

Khan, M.S., N. Ahmad and M.A. Khan, 2007. Genetic resources and diversity in dairy buffaloes of Pakistan. Pak. Vet. J., 27(4):201.

Maiwashe, A., K.A. Nephawe, R.R. Van der Westhuizen, B.E. Mostert and H.E. Theron, 2006. Rate of inbreeding and effective population size in four major South African dairy cattle breeds. S. Afr. J. Anim. Sci., 36 (1): 50 .

Meszaros, S.A., R.G. Banks and J.H.J. Van der Werf, 2000. Optimizing breeding structure in sheep flocks when inbreeding depresses genetic gain through effects on reproduction. Proceeding of the 6th World Congress On Genetics Applied to Livestock Production Armidale, Australia.

Meuwissen, T.H.E., 1997. Maximizing the response of selection with a predefined rate of inbreeding. J. Anim. Sci., 75: 934.

Meuwissen, T.H.E., 1991. The use of increased female reproductive rates in dairy cattle breeding schemes. Anim. Prod., 52: 21.

Mourad, K.A., 1990. Buffaloes in Egypt. Proceedings of FAO workshop on buffalo open nucleus breeding schemes (ONBS), Shuman, Bulgaria.

Phillips, A., 2001. Nucleus bull-breeding herds. Technote., 111: 1.

www.primaryindustry.nt.gov.au

Quinton, M., C. Smith and M.E. Goddard, 1992. Comparison of selection methods at the same level of inbreeding. J. Anim. Sci., 70: 1060 .

Sargolzaei, M., H. Iwaisaki and J.J. Colleau, 2006. CFC A Software Package for Pedigree Analysis and Monitoring Genetic Diversity, CFC manual.

SAS Procedures Guide, Version 9, 2004. SAS Inst., Inc., Cary, NC. 
Table 1. The estimates used in generating the simulated populations

\begin{tabular}{lll}
\hline Parameter & Estimate & Reference \\
\hline Average total milk yield (TMY) & $1884, \mathrm{~kg}$ & CISE, 2007 \\
Phenotypic standard deviation for TMY & $438, \mathrm{~kg}$ & CISE, 2007 \\
Average generation interval & $5.78, \mathrm{yr}$ & Mourad, 1990 \\
Heritability & 0.17 & CISE, 2007 \\
\hline
\end{tabular}

CISE: Cattle Information Systems/Egypt

Table 2. Least square means $(\overline{\mathbf{X}})$, standard error (SE) of the inbreeding coefficient in the nucleus changing by different nucleus size (p)

\begin{tabular}{cc}
$\mathbf{P}$ & $\overline{\mathbf{X}} \pm \mathbf{S E}$ \\
\hline 0.05 & $0.0032^{\mathrm{a}} \pm 0.0002$ \\
0.10 & $0.0029^{\mathrm{a}} \pm 0.0002$ \\
\hline
\end{tabular}

${ }^{\mathrm{a}}$ Means with same letter do not differ significantly $(P<0.05)$.

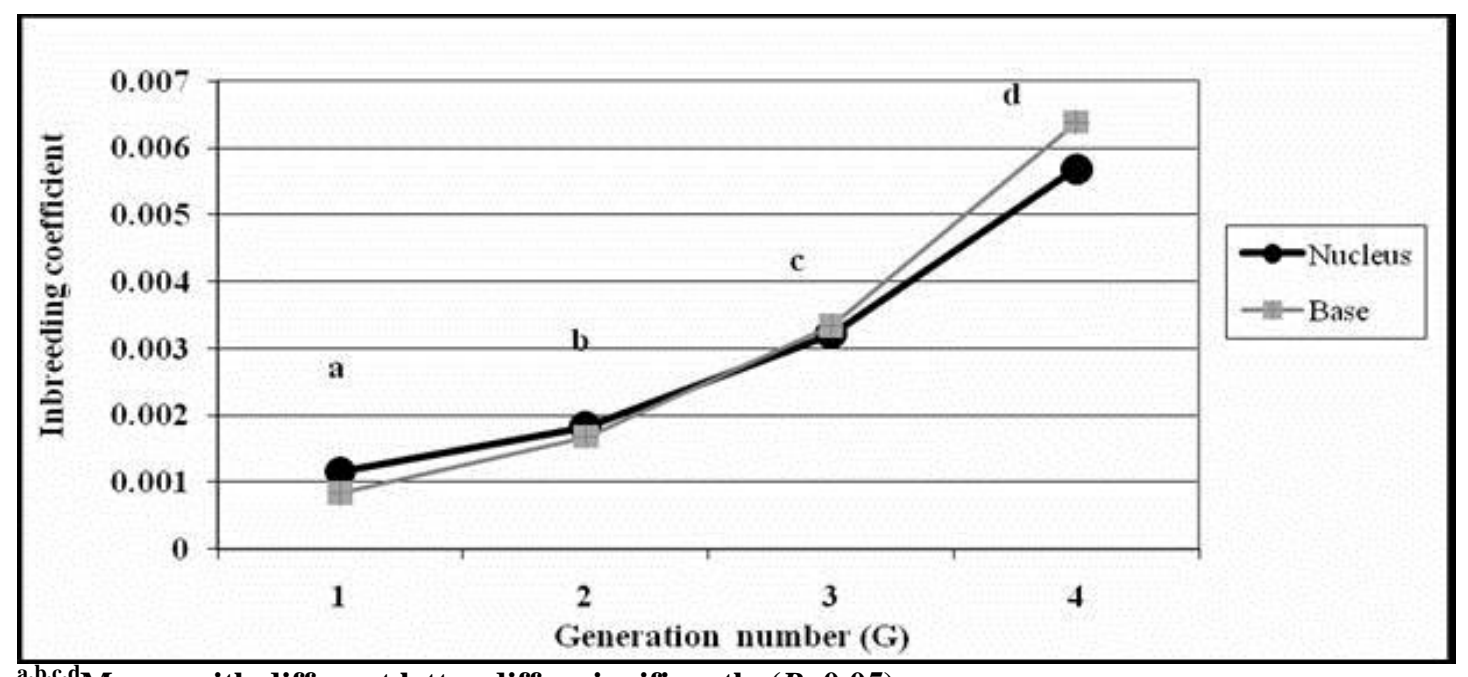

a,b,c,d Means with different letter differ significantly $(P<0.05)$.

$\mathrm{SE}$ in the nucleus $\pm \mathbf{0 . 0 0 0 1 8}$ and in the base \pm 0.00042

Fig. 1. The change of inbreeding coefficient by changing the generation number (G)

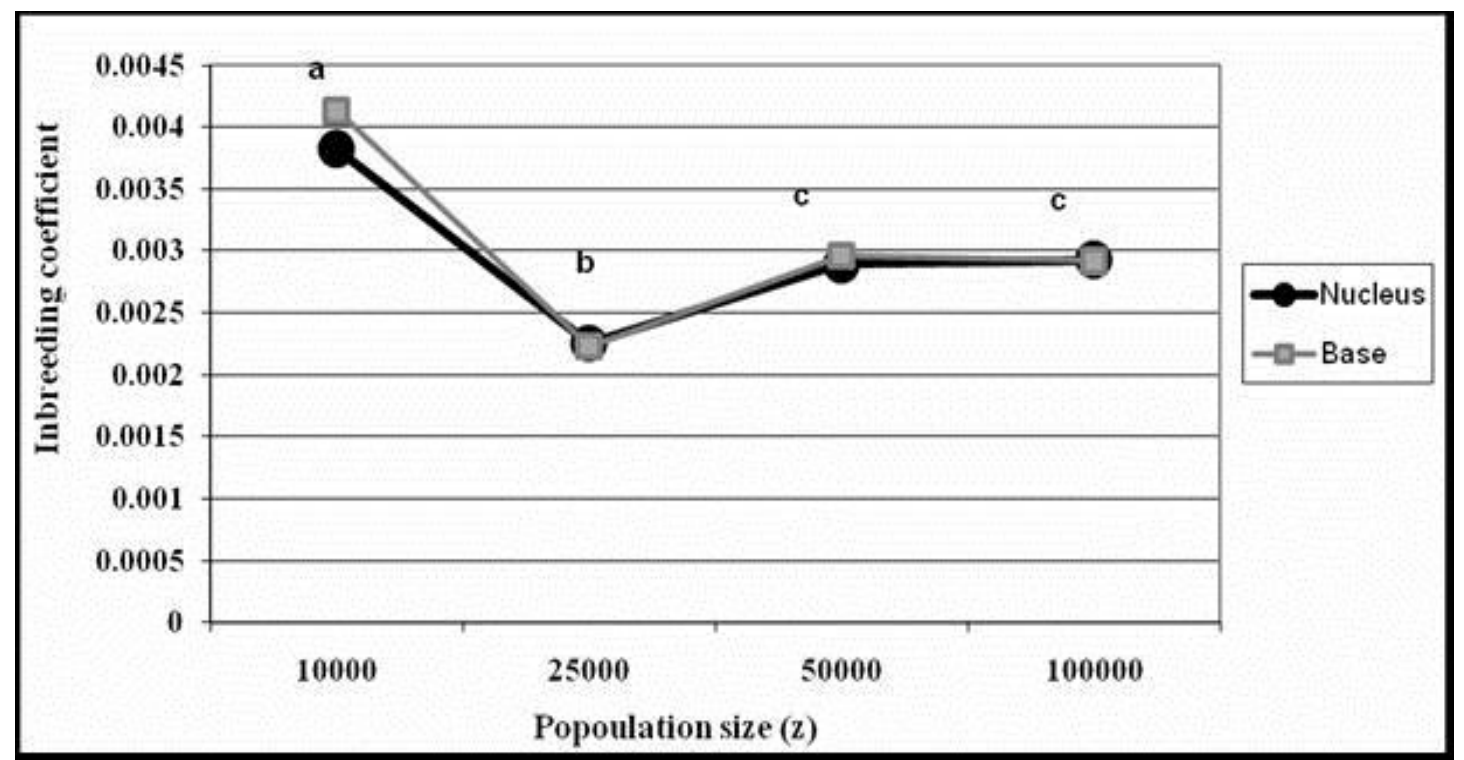

a,b,c Means with different letters differ significantly $(P<0.05)$

$\mathrm{SE}$ in the nucleus \pm 0.0002 and in the base \pm 0.0004

Fig. 2. The change of inbreeding coefficient by changing the population size $(z)$ 


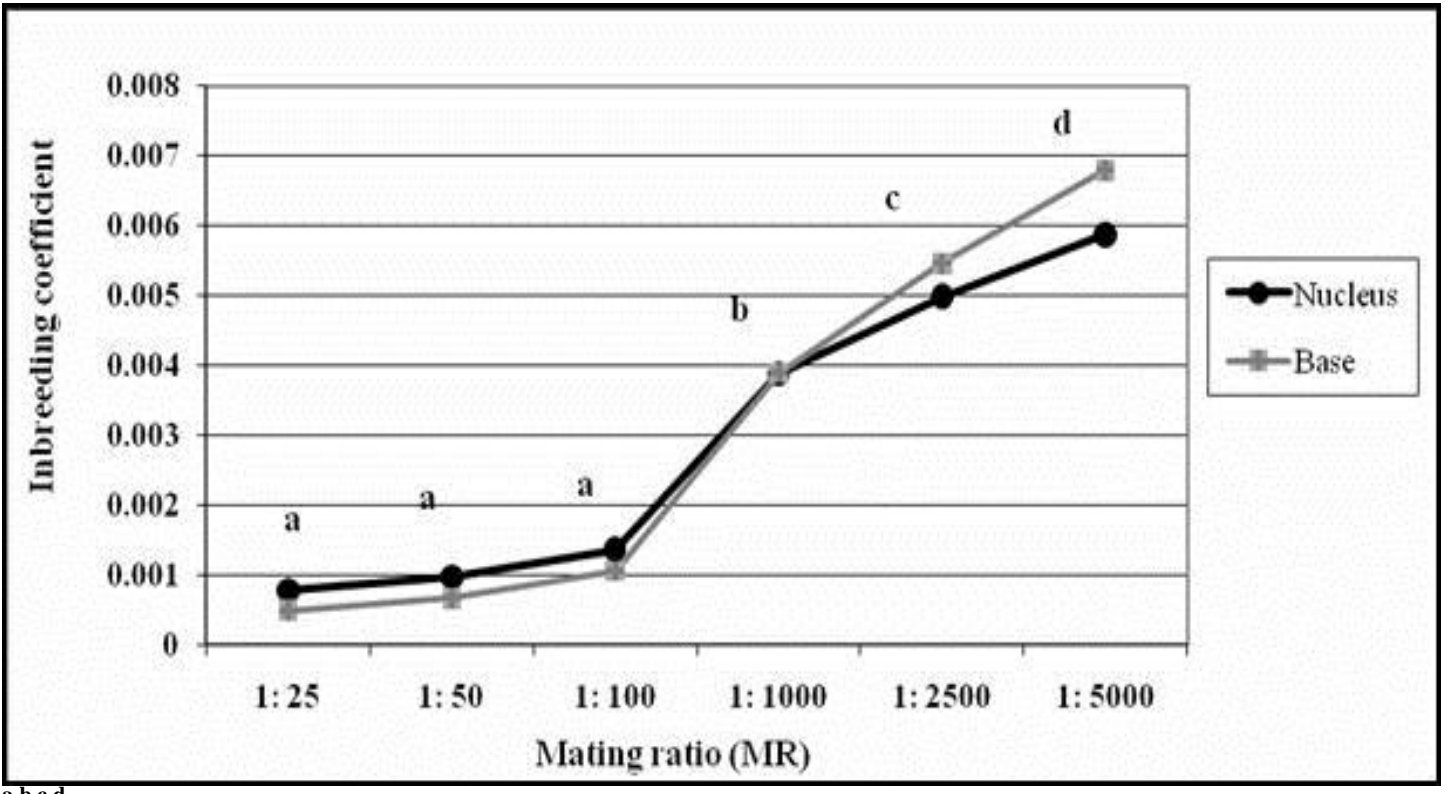

a,b,c,d Means with different letters differ significantly $(P<0.05)$.

$\mathrm{SE}$ in the nucleus $\pm \mathbf{0 . 0 0 0 2}$ and in the base $\pm \mathbf{0 . 0 0 0 5}$

Fig. 3. The change of inbreeding coefficient by changing mating ratio (MR)

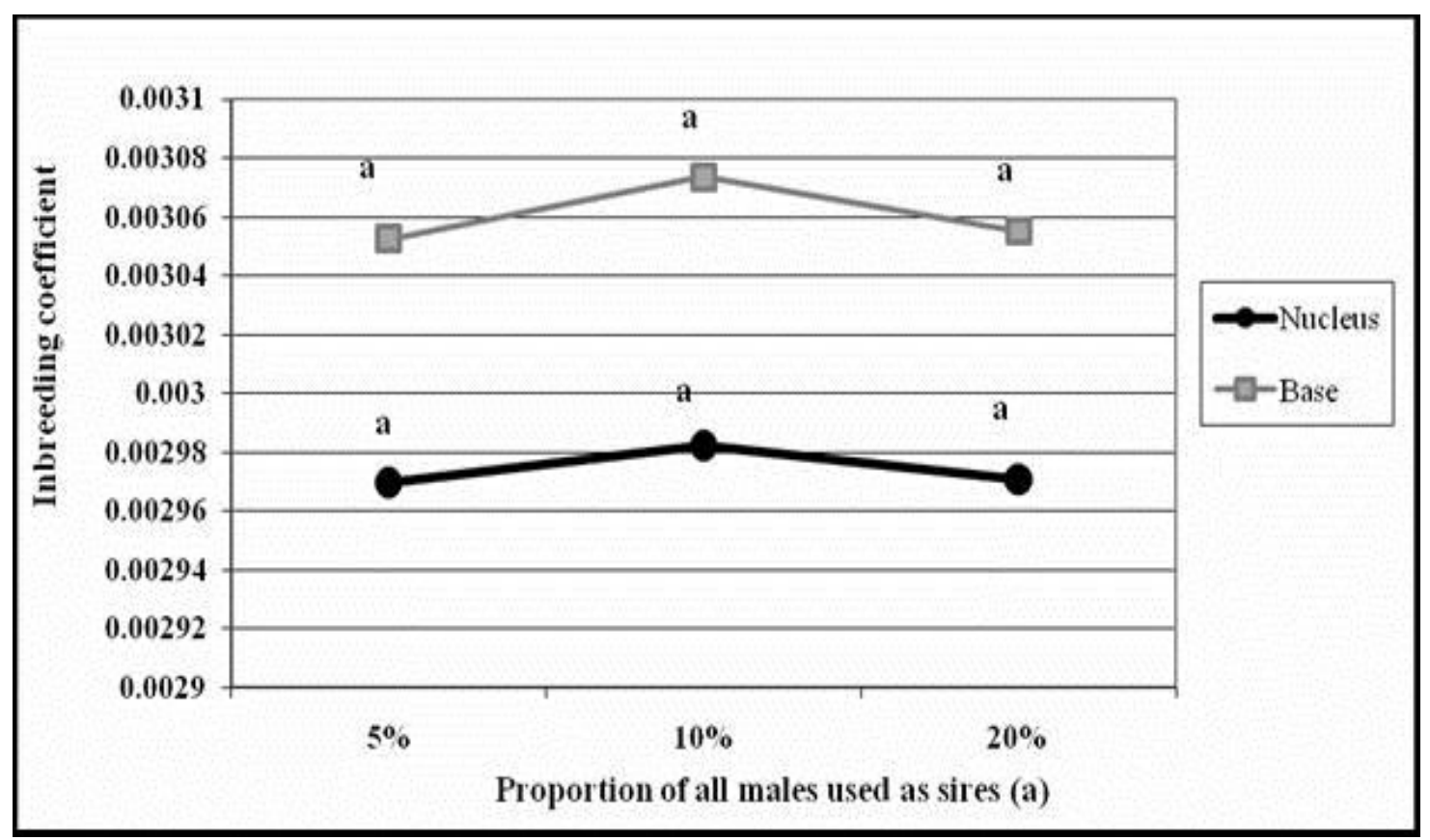

${ }^{a}$ Means with same letter do not differ significantly $(P>0.05)$.

$\mathrm{SE}$ in the nucleus \pm 0.0002 and in the base \pm 0.00045

Fig. 4. The change of inbreeding coefficient by changing proportion of males born used as sires $(a)$ 


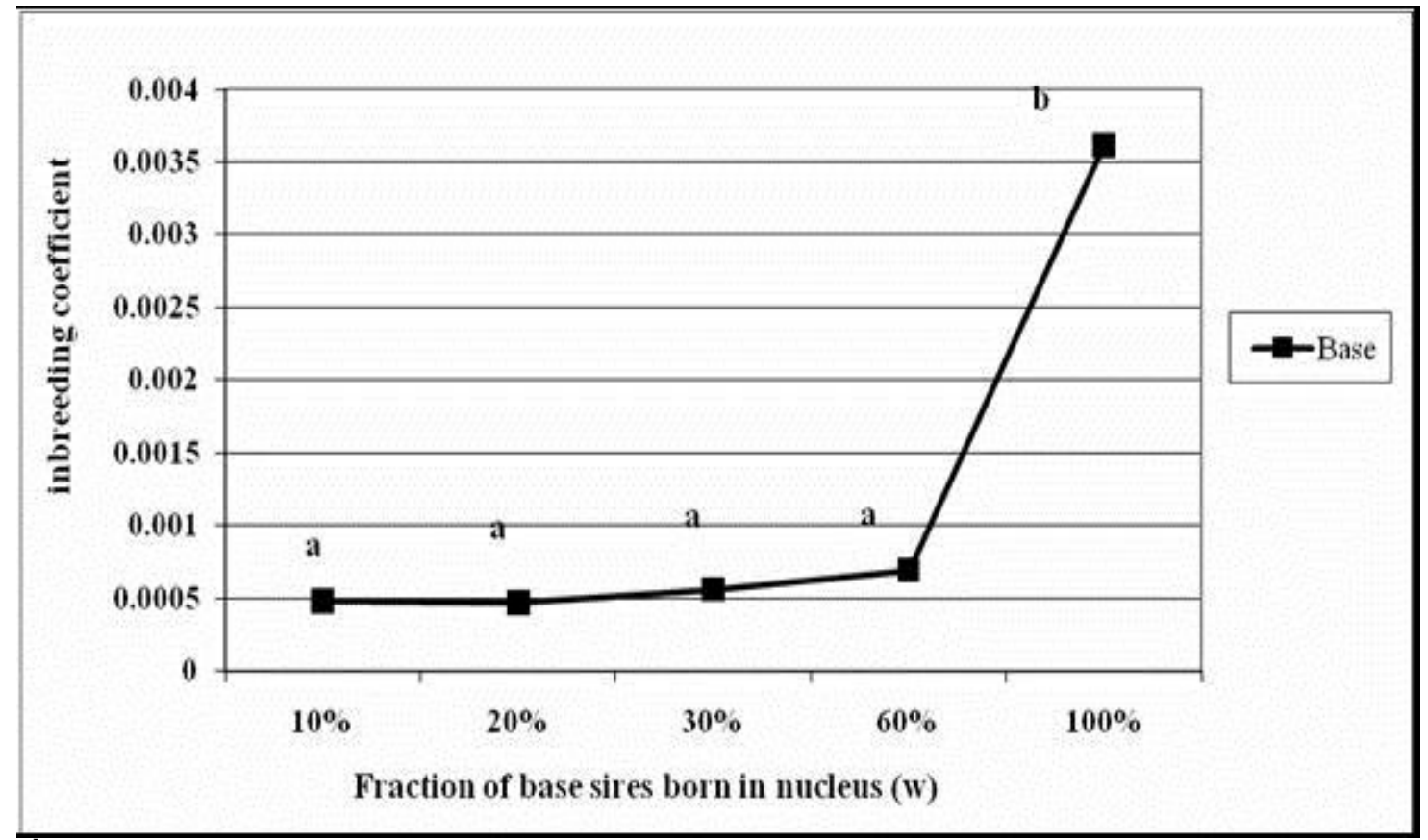

${ }_{\mathrm{a}, \mathrm{b}}$ Means with different letters differ significantly $(P<0.05)$.

SE \pm 0.0009

Fig. 5. The change of inbreeding coefficient by changing fraction of base sires born in nucleus (w)

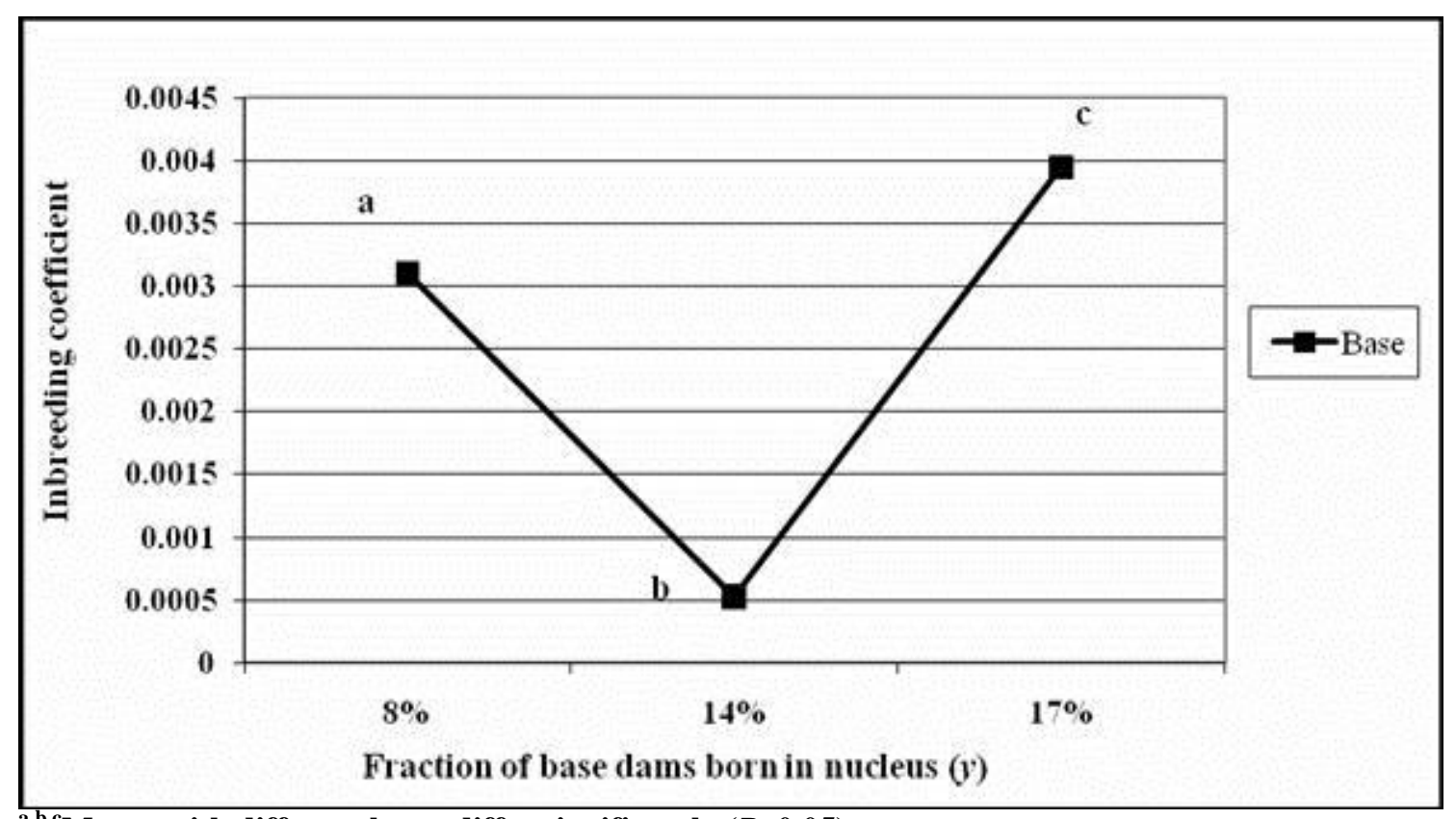

a,b,c Means with different letter differ significantly $(P<0.05)$.

$\mathrm{SE} \pm 0.0006$

Fig. 6. The change of inbreeding coefficient by changing fraction of base dams born in nucleus $(y)$ 


\section{معامل التربية الداخلية فى نظام التربية للنواة المفتوحة بإستخدام المحاكاة فى الجاموس المصرى}

أحمد إسماعيل سيد'، سامح عبد الفتاح محمد عبد السلام'، منال السيدّ، سامى أبو بكر' ا ـ قسم الإتتاج الحيوانس، كلية الزراعة، جامعة القاهرة، ؟ ـ قسم الإتتاج الحيوانى، كلية الزراعة، جامعة عين شمس

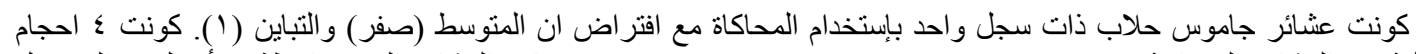

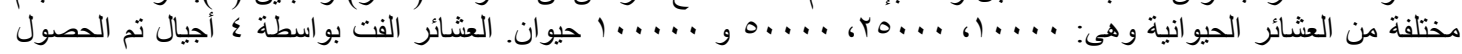

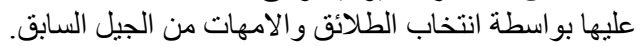

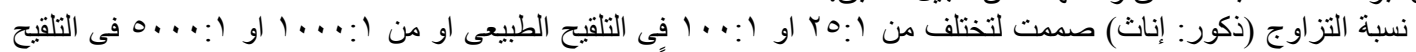

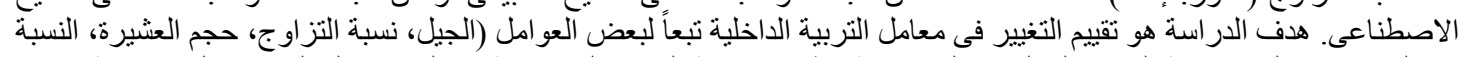

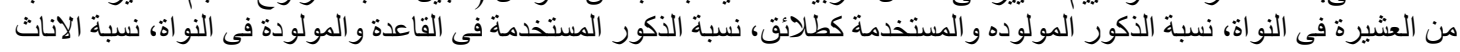

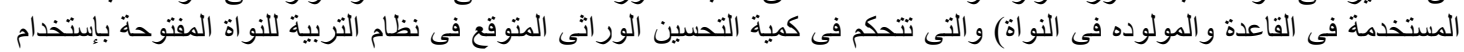

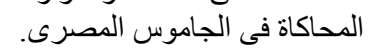

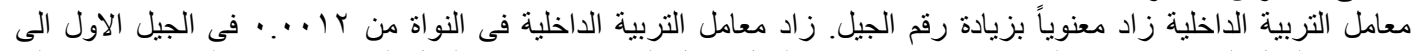

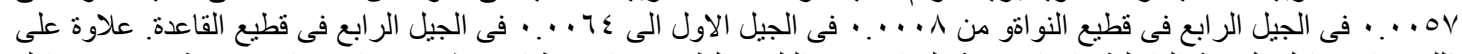

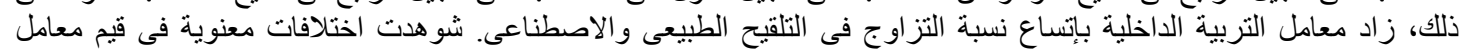

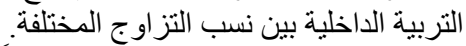

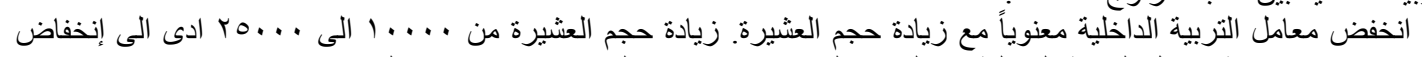

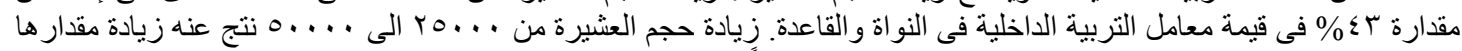

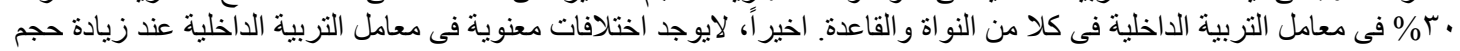

